\title{
Inflammatory Cytokines Facilitate the Sensitivity of P2X7 Receptors Toward Extracellular ATP at Neural Progenitor Cells of the Rodent Hippocampal Subgranular Zone
}

\author{
Juan Liu ${ }^{1,2}$, Muhammad Tahir Khan ${ }^{1}$, Yong Tang ${ }^{2}{ }^{-}$, Heike Franke ${ }^{1}$ and Peter Illes ${ }^{1,2, *}$ \\ 1 Rudolf-Boehm-Institut für Pharmakologie und Toxikologie, Universität Leipzig, 04107 Leipzig, Germany; \\ liujuan@cdutcm.edu.cn (J.L.); MuhammadTahir.Khan@medizin.uni-leipzig.de (M.T.K.); \\ heike.franke@medizin.uni-leipzig.de (H.F.) \\ 2 Acupuncture and Tuina School, Chengdu University of Traditional Chinese Medicine, Chengdu 610075, \\ China; tangyong@cdutcm.edu.cn \\ * Correspondence: peter.illes@medizin.uni-leipzig.de; Tel.: +49-341-9724614; Fax: +49-341-9724609
}

Received: 26 July 2018; Accepted: 16 August 2018; Published: 22 August 2018

\begin{abstract}
Organotypic hippocampal slice cultures were used to model the effects of neuroinflammatory conditions following an epileptic state on functional P2X7 receptors (Rs) of subgranular zone (SGZ) neural progenitor cells (NPCs). The compound, 4-aminopyridine (4-AP), is known to cause pathological firing of neurons, consequently facilitating the release of various transmitter substances including ATP. Lipopolysaccharide (LPS) and interleukin-1 $\beta$ (IL-1 $\beta$ ) both potentiated the dibenzoyl-ATP (Bz-ATP)-induced current amplitudes in NPCs, although via different mechanisms. Whereas LPS acted via promoting ATP release, IL-1 $\beta$ acted via its own receptor to directly influence P2X7Rs. Thus, the effect of LPS was inhibited by the ecto-ATPase inhibitor, apyrase, but not by the IL-1 $\beta$ antagonist, interleukin-1RA (IL-1RA); by contrast, the effect of IL-1 $\beta$ was inhibited by IL-1RA, but not by apyrase. Eventually, incubation with 4-AP upregulated the number of nestin/glial fibrillary acidic protein/P2X7R immunoreactive cells and their appropriate staining intensity, suggesting increased synthesis of P2X7Rs at NPCs. In conclusion, inflammatory cytokines accumulating after epilepsy-like neuronal firing may facilitate the effect of endogenous ATP at P2X7Rs of NPCs, thereby probably promoting necrosis/apoptosis and subsequent cell death.
\end{abstract}

Keywords: neural progenitor cells; extracellular ATP; P2X7 receptors; neuroinflammation; cytokines

\section{Introduction}

In the adult mammalian brain, the subgranular zone (SGZ) of the hippocampal dentate gyrus is one of the regenerative niches where neural progenitor cells (NPCs) are produced to give rise to the three main neural cell linages, i.e., neurons, astrocytes, and oligodendrocytes [1-3]. During their integration into the hippocampal circuits, NPCs pass through various consecutive developmental stages before differentiating to newborn and subsequently mature granule cells (glutamatergic projection neurons to CA3 pyramidal neurons).

The physiological functions of adult neurogenesis comprise emotions, learning, and memory, i.e., temporal separation, pattern separation, fear conditioning, high-resolution memory, and synaptic plasticity $[4,5]$. Some disease conditions, like Parkinson's disease, Huntington's disease, Alzheimer's disease, multiple sclerosis, stroke, depression, and temporal lobe epilepsy are also connected to abnormal adult neurogenesis [6]. The misbalance between NPC proliferation and disintegration may 
contribute to the establishment of a pathological pacemaker in the hippocampus after a one-time status epilepticus $[7,8]$.

The P2X7 receptor $(\mathrm{R})$ is a ligand-gated non-selective cationic channel, which has a uniquely low affinity for extracellular ATP, and is transformed to a large membrane pore on long-lasting exposure to high ATP concentrations $[9,10]$. In the central nervous system (CNS), P2X7Rs are present at microglia and astrocytes/oligodendrocytes, as well as NPCs; their existence at neurons is a much-debated issue $[10,11]$. Neuroinflammation is a common denominator of both epilepsy $[12,13]$ and P2X7R activation [14,15]. Hence, there are good reasons to speculate that the massive outflow of ATP from the epileptic focus may stimulate P2X7Rs, which are linked to the NLRP3/ASC inflammasome assembly, fostering the maturation and release of inflammatory cytokines such as interleukin-1 $\beta$ (IL-1 $\beta$ ), especially from microglia [16]. It was proposed that, preceding the activation of P2X7Rs, the stimulation of lipopolysaccharide (LPS)-targeted Toll-like receptors (TLRs) leads to the accumulation of cytoplasmic pro-IL-1 $\beta$, which is then processed to mature IL-1 $\beta$ under the influence of P2X7Rs [17].

We recently showed that pilocarpine-induced status epilepticus in rodents increases the sensitivity of P2X7Rs at SGZ NPCs toward ATP, consequently leading to a decrease in ectopic NPC/granule cell number in the hilus hippocampi $[2,18]$. Electrophysiological measurements in hippocampal slices prepared from such epileptic rats documented an increased sensitivity of their NPCs to ATP/dibenzoyl-ATP (Bz-ATP). This may lead to apoptosis/necrosis initiated via the caspase cascade and the loss of intracellular constituents of vital significance through the dilated P2X7R. When hippocampal slices were incubated with 4-aminopyridine (4-AP), a blocker of the transient outwardly directed potassium current $\left(I_{K(\mathrm{~A})}\right)$, to cause seizure-like activity in neurons, P2X7Rs at NPCs also became functionally upregulated [19].

We hypothesized that the pro-convulsive agent, 4-AP, causing P2X7R activation via endogenously released ATP may stimulate the synthesis and release of inflammatory cytokines which signal back to P2X7Rs and facilitate seizure susceptibility. In fact, incubation of organotypic hippocampal slices with LPS and IL-1 $\beta$ facilitated the P2X7R sensitivity of SGZ NPCs versus agonistic activation. This suggests that long-term P2X7R functions, such as apoptosis/necrosis, triggered by epileptic seizures are greatly facilitated under neuroinflammatory conditions.

\section{Materials and Methods}

\subsection{Preparation of Hippocampal Brain Slices and the Corresponding Organotypic Slice Cultures}

Hippocampal brain slices were obtained from C57BL/6J mice (bred in-house) or from mice overexpressing green fluorescent protein (GFP) under the control of the nestin gene ( $\operatorname{Tg}($ nestin/EGFP); gift from Helmut Kettenmann, Berlin). All animal use procedures were approved by the relevant Committee of Animal Protection (Regierungspraesidium Leipzig, Germany, CGZ216).

Mice pups (postnatal days 4-6; $\mathrm{P} 4-6$ ) were decapitated under $\mathrm{CO}_{2}$ anesthesia. The preparation and culturing of organotypic slices were similar to those described previously $[20,21]$. Briefly, the hippocampi were rapidly dissected and were placed in ice-cold preparation solution (minimum essential medium (MEM) supplemented with $2 \mathrm{mM}$ glutamine and $50 \mu \mathrm{g} / \mathrm{mL}$ gentamicin; all from Invitrogen, Carlsbad, CA, USA; the $\mathrm{pH}$ was adjusted to 7.3). Subsequently, transverse slices (thickness, $350 \mu \mathrm{m}$ ) were prepared with a Mcllwain tissue chopper (Saur Laborbedarf, Reutlingen, Germany), and were stored in Petri dishes filled with the same solution. Then, the slices were placed on moistened translucent membranes (six slices per membrane, 0.4- $\mu \mathrm{m}$ membranes; Millicell-CM, Millipore, Bedford, MO, USA). These membranes were transferred into six-well plates, each filled with $1 \mathrm{~mL}$ of incubation medium (50\% MEM, 25\% Basal Medium Eagle, 25\% heat-inactivated horse serum, supplemented with $2 \mathrm{mM}$ glutamine; all from Invitrogen; and $0.625 \%$ glucose purchased from Sigma-Aldrich, St. Louis, MO, USA). The slices were stored in an incubator at a constant temperature of $37^{\circ} \mathrm{C}$ and an atmosphere of $5 \% \mathrm{CO}_{2}$ in air; the medium was changed three times weekly. 
Organotypic brain slices were subjected to electrophysiological recordings and immunohistochemistry after 1-3 weeks in culture.

\subsection{Whole-Cell Patch-Clamp Recordings}

Organotypic cultured slices were superfused in an organ bath with $95 \% \mathrm{O}_{2}$ plus $5 \% \mathrm{CO}_{2}$-saturated artificial cerebrospinal solution (aCSF; $3 \mathrm{~mL} / \mathrm{min}$, room temperature). This aCSF had the following composition (in mM): $\mathrm{NaCl} 126, \mathrm{KCl} 2.5, \mathrm{CaCl}_{2}$ 2.4, $\mathrm{MgCl}_{2}$ 1.3, $\mathrm{NaH}_{2} \mathrm{PO}_{4} 1.2, \mathrm{NaHCO}_{3}$ 25, and glucose 11; the $\mathrm{pH}$ was 7.4, adjusted with $\mathrm{NaOH}$. To create a low divalent cation-containing (low $\mathrm{X}^{2+}$ ) solution, $\mathrm{MgCl}_{2}$ was omitted from the medium and the $\mathrm{CaCl}_{2}$ concentration was decreased to $0.5 \mathrm{mM}$. Neural progenitor cells and/or astrocytes in the subgranular zone of the hippocampal dentate gyrus were visualized with an upright interference contrast microscope and a $40 \times$ water-immersion objective (Axioskope FS, Carl Zeiss, Oberkochen, Germany). Patch pipettes were filled with intracellular solution of the following composition (in mM): K-gluconic acid 140, $\mathrm{NaCl} 10, \mathrm{MgCl}_{2}$ 1, HEPES 10, EGTA 11, Mg-ATP 1.5, Li-GTP 0.3; the pH was 7.2, adjusted with KOH. Pipettes (4-7 M $\Omega$ resistances) were pulled by a micropipette puller (P-97, Sutter Instruments, Novato, CA, USA) from borosilicate capillaries. The resting membrane potential $\left(V_{m}\right)$ of the cells was measured in the current-clamp mode of the patch-clamp amplifier (Multiclamp 700A; Molecular Devices, San Jose, CA, USA) immediately after establishing whole-cell access.

Neural progenitor cells were identified by their green fluorescence under an appropriate filter. Astrocytes (no fluorescence) and NPCs (green fluorescence) were discriminated from neurons by their failure to fire action potentials. For this purpose, hyper- and depolarizing current pulses $(-80,-20$, 40,100 , and $160 \mathrm{pA}$ ) were injected into the respective cells. Then, in the voltage-clamp recording mode of the amplifier, the holding potential of the astrocytes and NPCs were set at $-80 \mathrm{mV}$, near their membrane potentials. Multiclamp and pClamp software (Molecular Devices) were used to store the recorded data to perform offline analysis/filtering and to trigger the application system used.

\subsection{Drug Application Protocols}

Dibenzoyl-ATP $(300 \mu \mathrm{M})$ was pressure-ejected locally by means of a computer-controlled DAD-12 superfusion system (ALA Scientific Instruments, Farmingdale, NY, USA). The drug application tip touched the surface of the brain slice and was placed within 100-150 $\mu \mathrm{m}$ of the patched cell. Dibenzoyl-ATP $(300 \mu \mathrm{M})$ induced a low- $\mathrm{X}^{2+}$ medium inward current, whose amplitude was at the quasi-linear part of the semi-logarithmic concentration-response curves generated both in astrocytes [22] and NPCs [18]. Organotypic hippocampal slices were grown in incubation medium for one week before they were subjected to Bz-ATP $(300 \mu \mathrm{M})$ pulses (for $10 \mathrm{~s}$, every $2 \mathrm{~min}$, three times; the first response was discarded). All substances were present in the culturing medium for $14 \mathrm{~h}$, one day, or one week before using the organotypic slices for patch-clamp recordings. In some cases, the effect of Bz-ATP $(300 \mu \mathrm{M})$ was compared in a normal and low- $\mathrm{X}^{2+}$ medium.

\subsection{Multiple Immunofluorescence Labeling Under Confocal Microscopic Observation}

After the incubation period of three weeks, the Millicell membranes (Millipore, Bedford, MA, USA) were taken out and the hippocampal cultures were fixed for $2 \mathrm{~h}$ in a solution containing $4 \%$ paraformaldehyde (Merck, Darmstadt, Germany), $0.1 \%$ glutaraldehyde (Serva Electrophoresis, Heidelberg, Germany), and 0.2\% picric acid (Sigma-Aldrich) in $0.1 \mathrm{M}$ phosphate buffer (PB; pH 7.4). Afterward, cultures were rinsed intensively with $\mathrm{PB}$ and were cut into $50-\mu \mathrm{m}$ slices using the vibratome (Typ VT 1200S, Leica Biosystems, Wetzlar, Germany).

Following pre-incubation in a blocking solution (0.05 M tris-buffered saline (TBS), pH 7.6, supplemented with $5 \%$ fetal calf serum and $0.3 \%$ Triton X-100), the slices were incubated in a mixture of primary antibodies diluted in the blocking solution for $48 \mathrm{~h}$ at $4^{\circ} \mathrm{C}$. The following antibodies were used: anti-glial fibrillary acidic protein (GFAP; mouse, 1:1000; Sigma-Aldrich), anti-Iba1 (goat, 1:100; Abcam, Cambridge, UK), anti-nestin (mouse, 1:50; Millipore), or mouse anti-GFP (1:100; Clontech, 
Wisconsin, PE, USA), as well as anti-P2X7 (rabbit, 1:600; APR-004, Alomone Labs, Jerusalem, Israel). This incubation period was followed by rinsing in TBS. The simultaneous visualization of different primary antisera was performed with a mixture of secondary antibodies specific for the appropriate species immunoglobulin G (IgG; rabbit, mouse, goat). Carbocyanine (Cy)2- (1:400), Cy3- (1:1000), Cy5- (1:100) conjugated IgGs (all Jackson ImmunoResearch, West Grove, PE, USA) diluted in the blocking solution were applied for $2 \mathrm{~h}$ at room temperature. For nuclear staining, the slices were incubated with Hoechst 33342 (Hoe; final concentration $40 \mu \mathrm{g} / \mathrm{mL}$, Molecular Probes, Eugene, OR, USA) for $5 \mathrm{~min}$ in TBS at room temperature. After intensive washing and mounting on glass slides, sections were dehydrated and cover-slipped as described above. Control experiments were performed without primary antibodies or by pre-adsorption of the antibody with the immunizing peptides.

The multiple immunofluorescence was investigated using a confocal laser scanning microscope (LSM 510 Meta, Zeiss) using excitation wavelengths of $488 \mathrm{~nm}$ (argon, yellow-green Cy2 immunofluorescence), $543 \mathrm{~nm}$ (helium/neon, red Cy3 immunofluorescence), and $633 \mathrm{~nm}$ (helium/neon2, blue Cy5 labeling). An ultraviolet laser (362 nm) was used to excite the blue-cyan Hoe 33342 fluorescence.

\subsection{Materials}

The following drugs were used: interleukin-1 $\beta$ murine (IL-1 $\beta$; Biomol, Hamburg, Germany), antimycin A, 2' (3')-O-(4-benzoylbenzoyl)adenosine $5^{\prime}$-triphosphate triethylammonium salt (Bz-ATP), epidermal growth factor from mouse (EGF), fibroblast growth factor-2 (FGF-2), interleukin-1RA murine (IL-1RA), LPS from Escherichia coli, nerve growth factor- $\beta$ from mouse (NGF), and sodium iodoacetate (Sigma-Aldrich).

\subsection{Statistics}

Means \pm standard errors of the mean (SEM) are given throughout. SigmaPlot 13.0 was used for statistical evaluation (Systat Software Inc., Chicago, IL, USA). We tested for and found that, when using parametric tests, all sampled distributions satisfied the normality and equal variances criteria. Multiple comparisons between data were performed with a one-way analysis of variance (ANOVA) followed by the Holm-Sidak test. Two datasets were compared either using the parametric Student's $t$-test or the non-parametric Mann-Whitney rank sum test, as appropriate. A probability level of 0.05 or less was considered to be statistically significant.

\section{Results}

3.1. Sensitivity Increase of P2X7Rs at SGZ NPCs in Organotypic Hippocampal Slices Caused by Pre-Incubation with Lipopolysaccharide and Cytokines

Combination of four criteria can verify that Bz-ATP at a submaximal concentration of $300 \mu \mathrm{M}$ selectively activates the P2X7Rs in SGZ NPCs: (1) the responses to both Bz-ATP and ATP are potentiated in a low- $\mathrm{X}^{2+}$ bath medium; (2) Bz-ATP causes comparable inward currents at about 10-times lower concentrations than ATP itself; (3) the Bz-ATP effect is nearly abolished by the highly selective P2X7R antagonist A-438079; and (4) the Bz-ATP current exhibits a reversal potential around $0 \mathrm{mV}$, characteristic for non-selective cationic channels [18]. All of these criteria held true for SGZ NPCs in a slice preparation [18].

Therefore, we applied, in all subsequent experiments, $300 \mu \mathrm{M}$ Bz-ATP as a test concentration to investigate changes in P2X7R sensitivity. Furthermore, 4-AP (50 $\mu \mathrm{M}$; one-week incubation) facilitated the effect of Bz-ATP $(300 \mu \mathrm{M})$ on NPCs in hippocampal slice cultures [19]. This effect was thought to be due to a lengthening of the half amplitude duration of action potentials in dentate gyrus granule neurons increasing the release of glutamate and ATP onto SGZ NPCs [19]. Incubation with LPS (10 ng/mL) for $14 \mathrm{~h}$ had an effect similar to that of 4-AP (Figure 1A,B). It is noteworthy that only Bz-ATP-induced 
current responses measured in a low- $\mathrm{X}^{2+}$ medium exhibited potentiation, but not those measured in a normal external medium.

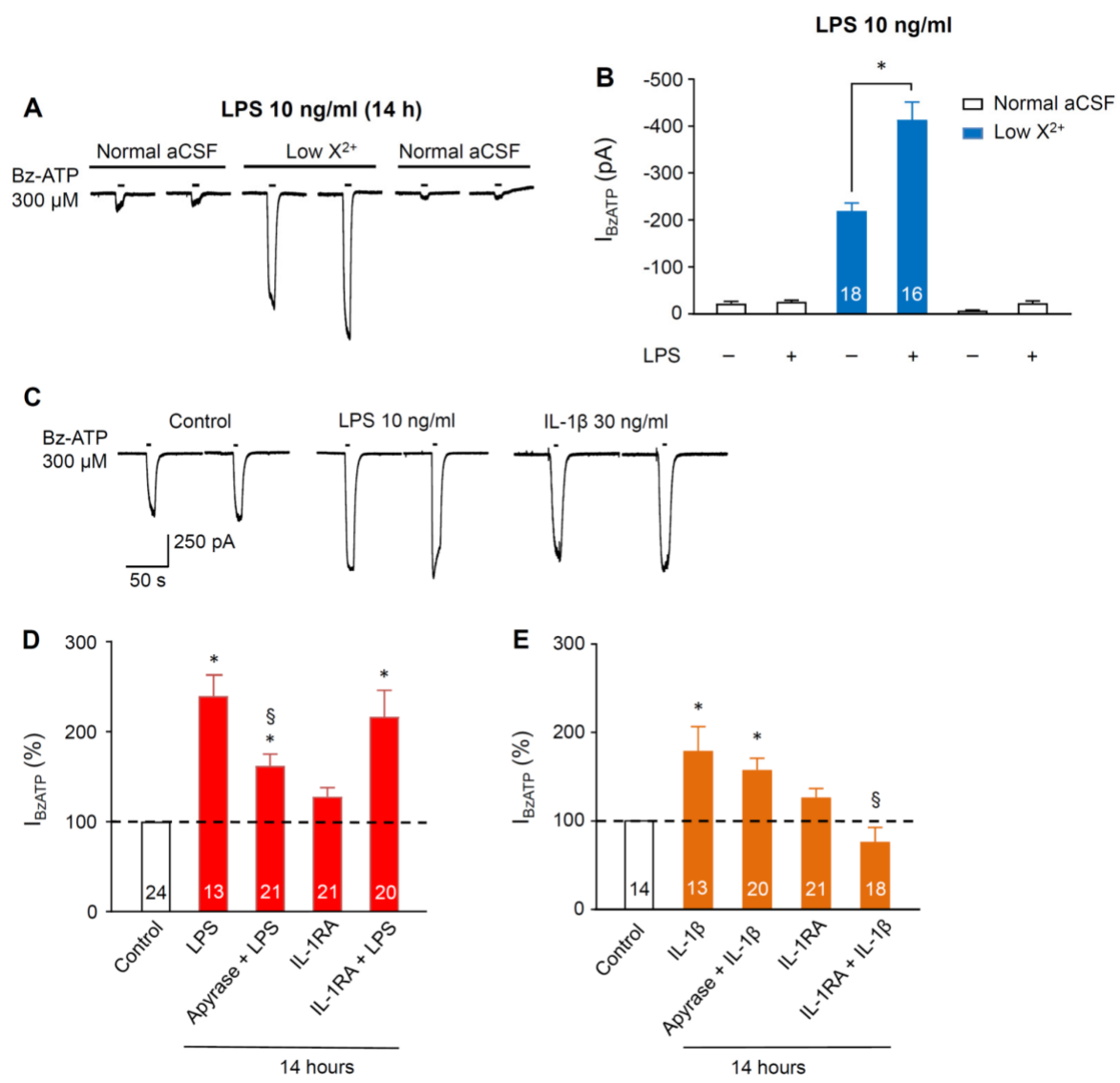

Figure 1. Effects of 4-aminopyridine (4-AP), lipopolysaccharide (LPS), and interleukin-1 $\beta$ (IL-1 $\beta$ ) on dibenzoyl-ATP (Bz-ATP)-induced current responses of neural progenitor cells (NPCs) located in organotypic hippocampal slices cultured for one week. Normal artificial cerebrospinal solution (aCSF) or low $\mathrm{X}^{2+}$ aCSF has been used. Lipopolysaccharide $(10 \mathrm{ng} / \mathrm{mL})$ and IL-1 $\beta(30 \mathrm{ng} / \mathrm{mL})$ were added either alone or together with apyrase (30 IU / mL), or interleukin-1RA murine (IL-1RA) $(100 \mathrm{ng} / \mathrm{mL})$ for the last $14 \mathrm{~h}$ of culturing. (A,B) Effect of LPS on the Bz-ATP $(300 \mu \mathrm{M})$-induced current amplitudes $\left(I_{\text {BzATP }}\right)$. Dibenzoyl-ATP was applied six times in total, both in the absence and presence of LPS. A normal external medium was changed to one which contained no $\mathrm{Mg}^{2+}$ and a low $\mathrm{Ca}^{2+}$ concentration (low $\mathrm{X}^{2+}$ ). Representative current tracings in the presence of LPS (A). Mean \pm standard error of the mean (SEM) of the indicated number of cells $(\mathbf{B})$. Lipopolysaccharide potentiated $I_{\text {BzATP }}$ in a low- $\mathrm{X}^{2+}$ medium only. The mean of two subsequent responses is shown in (B). ${ }^{*} p<0.05$; statistically significant difference between the respective pairs of currents recorded in the absence and presence of LPS. (C-E) Representative tracings show a potentiation of Bz-ATP $(300 \mu \mathrm{M})$ currents by incubation of hippocampal slices in culturing medium containing LPS or IL-1 $\beta$ (C). Dibenzoyl-ATP pulses were applied three times (the first response was discarded). Percentage potentiation of $I_{\text {BzATP }}$ by LPS alone, or in the combined presence of LPS plus apyrase, or LPS plus IL-1RA (D). Comparison was with $I_{\text {BzATP }}$ measured in a drug-free medium (control). Mean \pm SEM of the indicated number of cells in both (D) and (E). Percentage potentiation of $I_{\text {BzATP }}$ by IL-1 $\beta$ alone, or in the combined presence of IL-1 $\beta$ plus apyrase or IL-1 $\beta$ plus IL-1RA (E). Comparison was with $I_{\text {BzATP }}$ measured in a drug-free bath medium (control). The effect of IL-1RA on $I_{\text {BzATP }}$ in (E) was re-plotted from (D). ${ }^{*} p<0.05$; statistically significant difference from the control values. $\S p<0.05$; statistically significant difference from the effect of LPS (D) and IL-1 $\beta$ alone (E). 
Incubation with ATP $(10 \mu \mathrm{M})$ for $14 \mathrm{~h}$ caused a facilitation of the Bz-ATP-induced current $\left(I_{\text {BzATP }}\right)$; this effect was abolished by co-incubation of ATP with the ecto-ATPase apyrase (10 IU / mL; [19]) which by itself did not increase $I_{\text {BzATP. }}$. Therefore, it was concluded that the effect of ATP is, in fact, mediated by the activation of P2Rs. Apyrase also depressed the effect of co-applied LPS (10 ng/mL; $14 \mathrm{~h})$, indicating that LPS releases endogenous ATP which then supposedly acts at P2X7Rs (Figure 1C,D). By contrast, the IL-1 $\beta$ antagonist, IL-1RA (100 ng/mL; $14 \mathrm{~h}$ ), failed to influence the LPS effect (Figure 1D). Furthermore, IL-1 $\beta(100 \mathrm{ng} / \mathrm{mL})$ facilitated $I_{\text {BzATP, }}$ just as ATP and LPS did; however, this was via a different mechanism, because the effect of IL-1 $\beta$ was obliterated by IL-1RA, but not by apyrase (Figure 1C,E). We assume that exogenous ATP, as well as endogenous ATP released by LPS, activates P2X7Rs, thereby potentiating the action of Bz-ATP probably by allowing increased $\mathrm{Ca}^{2+}$ entry into the cells. By contrast, IL-1 $\beta$ may directly facilitate cationic fluxes through P2X7Rs apparently contradicting the confirmed permissive role of ATP for the LPS-induced secretion of IL- $1 \beta$ under our experimental conditions.

3.2. Sensitivity Increase of P2X7Rs at SGZ NPCs in Organotypic Hippocampal Slices Caused Pre-Incubation with Growth Factors, but not by Pre-Incubation with Reactive Oxygen Species or Metabolic Inhibitors

Neuroinflammation is mediated not only by cytokines, but also by growth factors, and it follows the neuronal damage caused by metabolic limitation. It is a major condition in stroke pathophysiology and contributes to secondary neuronal damage in both acute and chronic stages of the ischemic injury [23]. Neuroinflammation and epilepsy are also thoroughly interrelated pathological events $[13,24,25]$.

Therefore, we incubated brain slice cultures for one day or one week with NGF $(30 \mathrm{ng} / \mathrm{mL}$ ) which increased $I_{\mathrm{BzATP}}$ of NPCs in comparison with controls (Figure 2A,B). The combination of EGF $(20 \mathrm{ng} / \mathrm{mL})$ with FGF-2 $(10 \mathrm{ng} / \mathrm{mL})$ for one week had a similar effect. Eventually, organotypic hippocampal slice cultures were damaged either by the free oxygen radical, $\mathrm{H}_{2} \mathrm{O}_{2}(10 \mu \mathrm{M}$; 14-h incubation), or by the combined application of antimycin $(25 \mathrm{nM})$ and sodium iodoacetate $(10 \mu \mathrm{M})$ for $14 \mathrm{~h}$ to block oxidative phosphorylation and glycolysis, respectively (Figure 1C,D; [26]). Both oxidative and metabolic damage failed to cause a potentiation of Bz-ATP currents at NPCs. We did not measure the effect of $\mathrm{H}_{2} \mathrm{O}_{2}$ and antimycin plus sodium iodoacetate on $I_{\mathrm{BzATP}}$ after longer-lasting incubation of hippocampal slices (e.g., one week); it is quite possible that, under these conditions, a secondary neuroinflammation would cause potentiation of the Bz-ATP-induced current responses. 


\section{A}
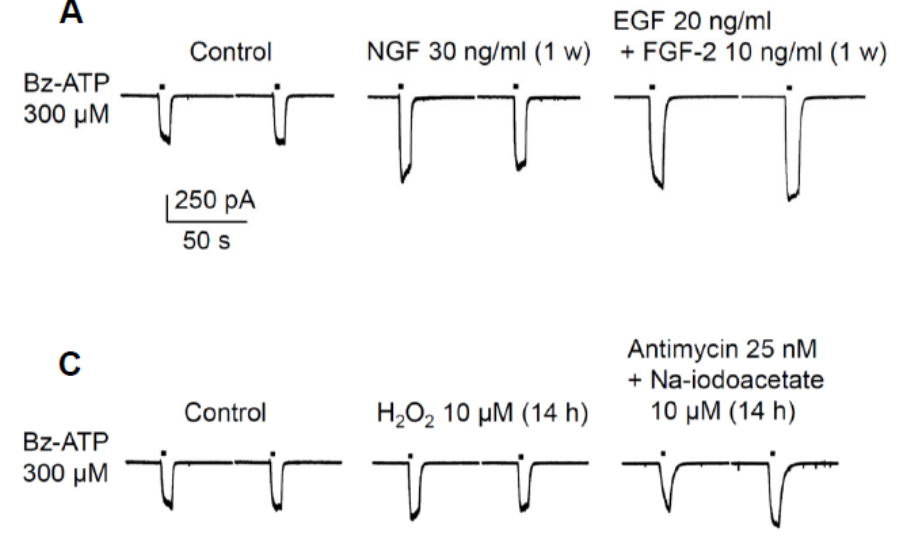

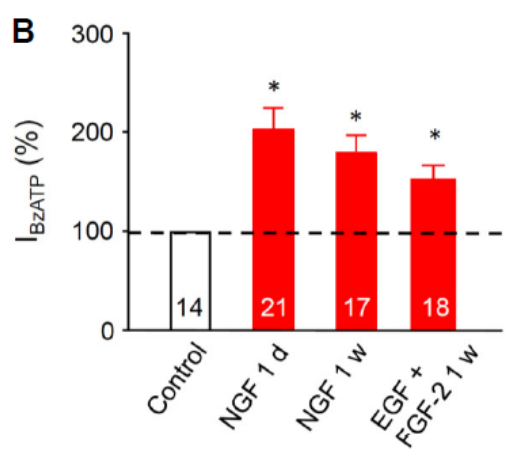

D

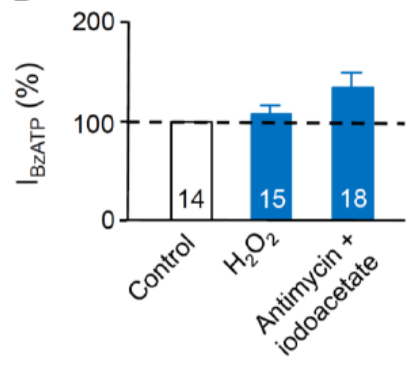

Figure 2. Effects of growth factors or the in vitro modelling of reperfusion injury/metabolic limitation on Bz-ATP-induced current responses of NPCs located in organotypic hippocampal slices cultured for one week. (A,B) Nerve growth factor (NGF; $30 \mathrm{ng} / \mathrm{mL}$ ) or epidermal growth factor (EGF; $20 \mathrm{ng} / \mathrm{mL}$ ) plus fibroblast growth factor-2 (FGF-2; $10 \mathrm{ng} / \mathrm{mL}$ ) were present in the external medium for the whole week $(1 \mathrm{w})$. In some experiments, NGF was present only for the last $24 \mathrm{~h}$ of cultivation $(1 \mathrm{~d})$. Representative tracings show potentiation of the Bz-ATP $(300 \mu \mathrm{M})$ currents $\left(I_{\text {BzATP }}\right)$ by NGF or EGF plus FGF-2 (A). Dibenzoyl-ATP pulses were applied three times (the first response was discarded). Percentage potentiation of $I_{\mathrm{BzATP}}$ by NGF for the time periods indicated, or in the combined presence of EGF plus FGF-2 for one week (B). Comparison was with $I_{\text {BzATP }}$ measured in a drug-free bath medium (control). Mean \pm SEM of the indicated number of cells. (C,D) $\mathrm{H}_{2} \mathrm{O}_{2}(10 \mu \mathrm{M})$ or antimycin $(25 \mathrm{nM})$ plus Na-iodoacetate $(10 \mu \mathrm{M})$ were present in the external medium for the last $14 \mathrm{~h}$ of culturing only. Representative tracings show no changes of Bz-ATP $(300 \mu \mathrm{M})$ currents by $\mathrm{H}_{2} \mathrm{O}_{2}$ or antimycin plus Na-iodoacetate (C). Mean \pm SEM of the indicated number of cells $(\mathbf{D}) .{ }^{*} p<0.05$; statistically significant difference from the control value.

\subsection{P2X7R Immunoreactivity in Organotypic Hippocampal Slice Cultures}

The exemplary structure of the hippocampus in a three-week-old organotypic slice culture shows cell bodies stained with Hoechst 33342 (Hoe) in a black-and-white confocal laser-scanning microscopic picture (Figure 3A). Incubation with a 4-AP $(50 \mu \mathrm{M})$-containing medium after the initial two weeks of culturing for a further week did not cause an appreciable change in the gross structural view (not shown). Subsequently, we evaluated the colored images in the SGZ of the hippocampal dentate gyrus after mechanical removal of the glial cap, interfering with visibility. For this purpose about $50 \mu \mathrm{m}$ of the superficial tissue layers were cut away from the slice culture by means of a vibratome (VT1200, Leica Biosystems). 

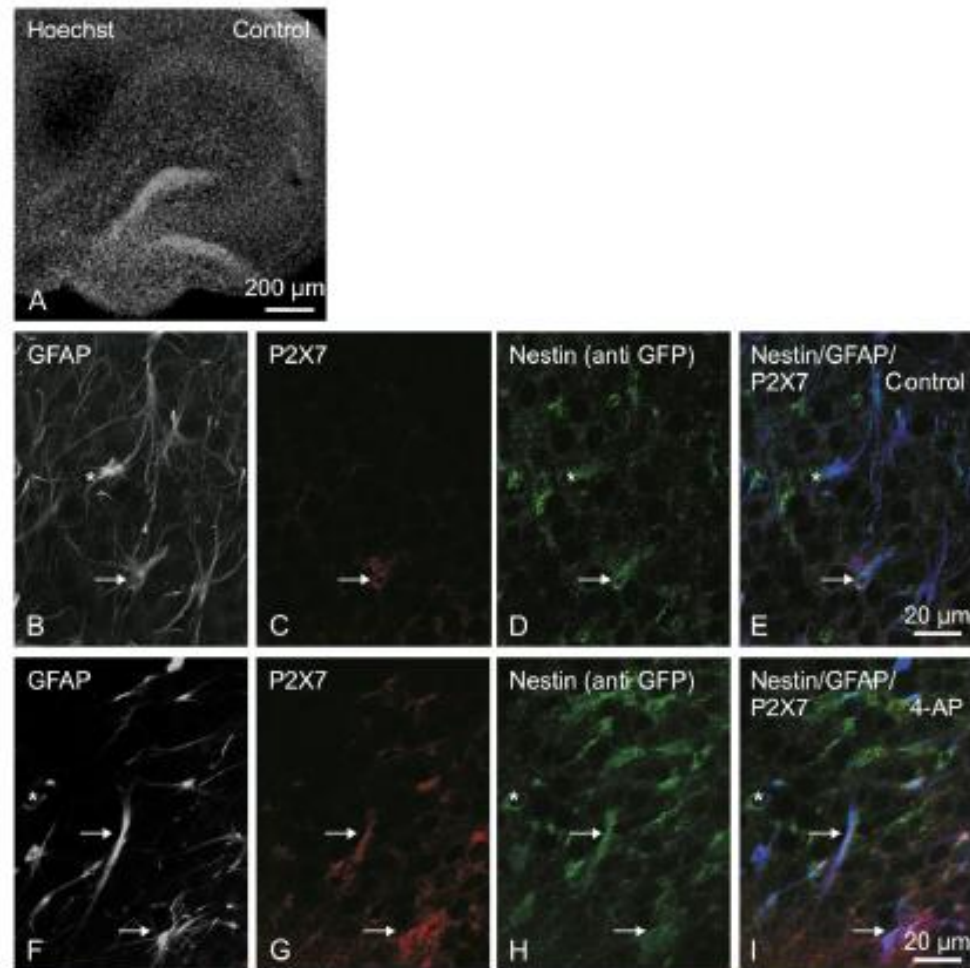

Nestin/GFAP/
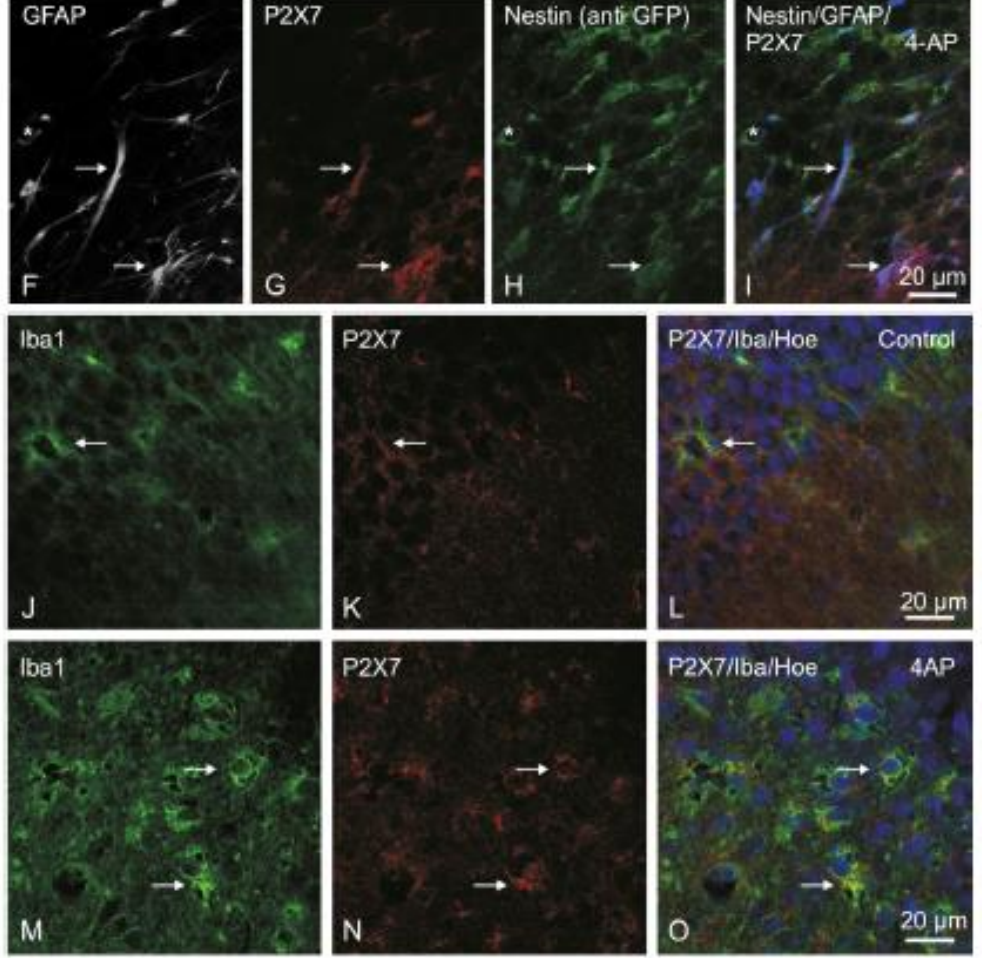

Figure 3. P2X7 receptor (R) immunoreactivity (IR) in three-week-old organotypic hippocampal slice cultures of mice overexpressing green fluorescent protein under the control of the nestin gene (Tg(nestin-EGFP)). (A) Black-and-white structure of the hippocampus under confocal laser-scanning microscopic observation; the cell nuclei were stained with Hoechst 33342 (Hoe) here and in (L) and (O). Images show, in the specimens, various immunoreactive (IR) structures in the subgranular zone of the dentate gyrus after labeling with specific antibodies. Arrows mark the overlaying IR structures throughout. Asterisks mark anti-glial fibrillary acidic protein (GFAP)/nestin double IR, with no staining for P2X7 in (B-E) and (F-I). (B-E) Weak GFAP-, nestin-, and P2X7R-IR structures and their overlay. (F-I) Stronger GFAP-, nestin-, and P2X7-IR structures and their overlay after incubation with 4-AP $(50 \mu \mathrm{M})$ for the last week of cultivation. The number of triple IR cells also increased. (J-L) Ibaand P2X7R-IR structures are co-localized on microglial cells. (M-O) Incubation with 4-AP caused an increase in the number of co-labeled cells and their intensity of staining for Iba/P2X7-IR structures. Scale bars, $200 \mu \mathrm{m}$ (A) and $20 \mu \mathrm{m}$ (B-O). Representative snapshots obtained from three to four animals per group. 
Because the specimens were prepared from $\operatorname{Tg}($ nestin/EGFP) mice, the staining with anti-EGFP labeled nestin-immunoreactive (IR) NPCs. We observed weak GFAP-, P2X7-, and nestin-IR NPCs in the control SGZ (Figure 3B-E). Incubation of the slices with 4-AP caused upregulation of the nestin/GFAP/P2X7-IR cell number and the appropriate staining intensity (Figure 3F-I). Whereas radial glia-like type 1 NPCs exhibit IRs for both GFAP and nestin, astrocytes are IR for GFAP only. We did not observe P2X7-IR at these astrocytes. However, it should be mentioned that, in spite of the lack of P2X7-IR at astrocytes, functional P2X7Rs can be detected at this cell type, e.g., in the prefrontal cortex, especially in a low- $\mathrm{X}^{2+}$ medium [22]. We assume that the density of P2X7Rs at astrocytes is much lower than the density of P2X7Rs at NPCs.

In the hippocampal cell formation and on the surface of the tissue slices, P2X7-IR was observed on activated microglia (marked by anti-Iba1; Figure 3J-L); both IRs increased after incubation with 4-AP (Figure 3M-O).

Hence, in accordance with the potentiation of the Bz-ATP-induced currents of NPCs by a long-lasting treatment with 4-AP, both the number of nestin/GFAP/P2X7 triple-labeled type 1 NPCs and the staining intensity for the investigated antibodies at these cells were upregulated. In other words, the facilitated P2X7R function appears to be due to an enhancement of protein synthesis, and probably also to alleviated post-receptor signaling due to the activation of a calcium/calmodulin binding site at the C-terminus of the P2X7R [27].

\section{Discussion}

The main findings of this study were the following: (1) incubation with LPS, IL-1 $\beta$, or growth factors (NGF, EGF, or FGF) facilitated the Bz-ATP sensitivity of NPCs located in the SGZ of organotypic hippocampal slice cultures; (2) incubation with the reactive oxygen species, $\mathrm{H}_{2} \mathrm{O}_{2}$, or the blockade of oxidative phosphorylation and glycolysis (antimycin plus sodium iodoacetate) had no comparable effect; (3) incubation with 4-AP caused upregulation of the nestin/GFAP/P2X7-IR cell number and the appropriate staining intensity, indicating that a facilitated P2X7R function may be due to enhanced protein synthesis, and probably also to alleviated post-receptor signaling in NPCs.

Experimental evidence in rodents demonstrates that seizures largely increase the levels of inflammatory mediators in brain regions involved in the generation and propagation of epileptic activity $[13,24,25]$. Prototypic inflammatory cytokines, such as IL-1 $\beta$, IL-6, and tumor necrosis factor- $\alpha$ (TNF- $\alpha)$, are upregulated in activated microglia and astrocytes, before triggering a cascade of downstream inflammatory events that also involve neurons and endothelial cells of the blood-brain barrier. In models of chronic inflammation, such as transgenic mice systemically overexpressing IL- 6 or TNF- $\alpha$, a reduced seizure threshold was observed, which predisposes the brain to seizure-induced neuronal loss [28]. Furthermore, TNF- $\alpha$ and IL-10 were associated with the regulation of seizure duration in experimental kindling models [29]. On the contrary, mild inflammatory response evoked by LPS during a critical period of development caused a long-lasting increase in hippocampal excitability in vitro, and enhanced seizure susceptibility to the convulsants, pilocarpine, kanic acid, and pentetrazol [30]. It was concluded that cytokine-induced modifications in brain excitability underlying seizure phenomena involve both the rapid post-translational and the long-term transcriptional changes in voltage-gated and ligand-gated ion channels, as well as cytokine-mediated changes in genes involved in neurotransmission and synaptic plasticity [31,32].

In view of the contribution of neuro/glio-inflammation to epileptogenesis, we investigated the effect of LPS on $I_{\mathrm{BzATP}}$ of NPCs, which is supposed to release IL-1 $\beta$, e.g., from microglia/macrophages only in case of the co-stimulation of permissive P2X7Rs [14,15,33]. Experiments in a low- $\mathrm{X}^{2+}$ external medium showed an increase in $I_{\text {BzATP }}$ by pre-treatment of the organotypic slice cultures with both 4-AP [19] and LPS (present paper). A potentiation by a low divalent cation-containing external medium of the agonist effects at P2X7Rs are most probably due to the removal of an allosteric block exerted by $\mathrm{Ca}^{2+}$ [34]. A low extracellular $\mathrm{Ca}^{2+} / \mathrm{Mg}^{2+}$ concentration may, on the one hand, induce pathological 
firing in hippocampal CA1 and CA3 pyramidal cells in vitro, and, on the other hand, it corresponds to the ionic constitution of the extracellular microenvironment during seizures in vivo [35].

It was an unexpected finding that LPS facilitated $I_{\text {BzATP }}$ via the release of ATP without the involvement of IL-1 $\beta$ receptors; apyrase, but not IL-1RA, depressed the LPS-induced increase of P2X7R currents at NPCs. It was reported recently that a long-lasting stimulation of P2X7Rs by ATP increases the sensitivity of this receptor to Bz-ATP [19]. By contrast, IL-1 $\beta$ itself potentiated $I_{\text {BzATP }}$ via activation of an interleukin 1 receptor (IL-1R), because its effect was antagonized by the selective IL-1R antagonist, IL-1RA, but not apyrase. Thus, two different mechanisms appear to result in an increased sensitivity of P2X7Rs toward ATP, one of them via a facilitated ATP release and the other via the direct stimulation of P2X7Rs by inflammatory cytokines. We assume that, in both cases, increased $\mathrm{Ca}^{2+}$ entry into the cells occurs, with subsequent occupation of an intracellular $\mathrm{Ca}^{2+} /$ calmodulin binding motif at the C-terminus of the P2X7R, leading to a potentiation of $I_{\text {BzATP }}$ [27], or to increased trafficking of intracellular P2X7Rs to the plasma membrane. It should be pointed out that IL-1 $\beta$ is mainly released from microglial cells, which thereby take a central position in causing a conductance increase of P2X7Rs at NPCs. Of course it is possible that pre-incubation with 4-AP, ATP, LPS, and IL-1 $\beta$ all potentiate the Bz-ATP-induced current by facilitating a non-P2X7R-mediated component of $I_{\text {BzATP }}$ (Reference [19] and present paper). This is, however, unlikely; in previous experiments, we found that the selective P2X7R antagonist, A-438079, almost completely inhibited the 4-AP-potentiated I Therefore, it is tentatively suggested that, because the last link in the sequence of events triggered by 4-AP and IL- $\beta$ is identical (i.e., an elevated intracellular $\mathrm{Ca}^{2+}$ concentration), A-438079 could block also the IL-1 $\beta$-potentiated $I_{\text {BzATP. }}$

Proliferation of reactive astrocytes termed astrogliosis is mediated not only by ATP acting at P2X7Rs, but also by additional nucleotide receptors of the P2X and P2Y types [36,37]. However, ATP is only one of the numerous endogenous factors determining astrogliosis, acting alone or together with cytokines (IL, TNF, or interferons), growth factors (FGF-2 or leukemia inhibitory factor), neurotransmitters (glutamate or noradrenaline), reactive oxygen radicals, nitric oxide, etc. [38]. In order to elucidate a possible role of various growth factors in the increased function of P2X7Rs at hippocampal NPCs, we pre-treated our organotypic brain slices with NGF or EGF plus FGF-2. In fact, all growth factors investigated potentiated $I_{\text {BzATP }}$ under the present experimental conditions.

Medial cerebral artery occlusion as a model of focal cerebral ischemia leads to a massive outflow of ATP from damaged CNS cells and upregulates P2X7R-IR in the penumbra of the damaged brain area $[39,40]$. There is an early microglial response associated with the activation of this cell type followed by a late response restricted to neurons and astrocytes. The blocking of P2X7Rs decreased the infarct size, brain edema, and neurological deficits after cerebral infarction [41,42]. P2X7R antagonists also ameliorated delayed neuronal death after transient global ischemia $[43,44]$. Because in vitro ischemia in cerebrocortical cell cultures caused supersensitivity of P2X7Rs to their agonists [45], we investigated whether the free oxygen radical, $\mathrm{H}_{2} \mathrm{O}_{2}$, known to be produced during reperfusion of brain tissue following a temporary stop of blood flow, facilitates I BzATP in SGZ NPCs. Neither $\mathrm{H}_{2} \mathrm{O}_{2}$ nor the combined application of antimycin and sodium iodoacetate, to block oxidative phosphorylation and glycolysis, respectively, had any effect on the sensitivity of P2X7Rs at NPCs.

In conclusion, our in vitro experiments supported the hypothesis that the increased release of ATP from granule cells onto the hippocampal SGZ during a status epilepticus might foster the proliferation of NPCs $[2,18]$. Subsequently, proliferating NPCs migrate into ectopic locations, differentiate into mature neurons, and become integrated into pathological neuronal circuits. The activation of P2X7Rs by ATP in combination with the neuroinflammatory stimulation of P2X7Rs by cytokines causes necrosis/apoptosis of NPCs, thereby potentially preventing these deleterious processes. Thus, P2X7Rs could inhibit the transition of a one-time status epilepticus (possibly febrile seizures in childhood/early adolescence [46]) into chronic limbic epilepsy in humans. 
Author Contributions: Conceptualization, P.I. Data curation, P.I. and J.L. Formal analysis, Y.T. Funding acquisition, Y.T. Investigation, J.L., M.T.K., and H.F. Methodology, M.T.K. and H.F. Project administration, Y.T. Supervision, P.I., Y.T., and H.F. Validation, J.L. Writing-original draft, P.I.

Funding: This research was funded by the Deutsche Forschungsgemeinschaft (DFG; IL-20/21-1) and the Sino-German Centre for the Promotion of Science (GZ919).

Acknowledgments: The expert technical assistance by Katrin Becker is gratefully acknowledged.

Conflicts of Interest: The authors declare no conflict of interest.

\section{References}

1. Jessberger, S.; Gage, F.H. Adult neurogenesis: Bridging the gap between mice and humans. Trends Cell. Biol. 2014, 24, 558-563. [CrossRef] [PubMed]

2. Tang, Y.; Illes, P. Regulation of adult neural progenitor cell functions by purinergic signaling. Glia 2017, 65, $213-230$. [CrossRef] [PubMed]

3. Oliveira, A.; Illes, P.; Ulrich, H. Purinergic receptors in embryonic and adult neurogenesis. Neuropharmacology 2016, 104, 272-281. [CrossRef] [PubMed]

4. Braun, S.M.; Jessberger, S. Adult neurogenesis: Mechanisms and functional significance. Development 2014, 141, 1983-1986. [CrossRef] [PubMed]

5. Aimone, J.B.; Li, Y.; Lee, S.W.; Clemenson, G.D.; Deng, W.; Gage, F.H. Regulation and function of adult neurogenesis: From genes to cognition. Physiol. Rev. 2014, 94, 991-1026. [CrossRef] [PubMed]

6. Liu, H.; Song, N. Molecular Mechanism of Adult Neurogenesis and its Association with Human Brain Diseases. J. Cent. Nerv. Syst. Dis. 2016, 8, 5-11. [CrossRef] [PubMed]

7. Parent, J.M.; Yu, T.W.; Leibowitz, R.T.; Geschwind, D.H.; Sloviter, R.S.; Lowenstein, D.H. Dentate granule cell neurogenesis is increased by seizures and contributes to aberrant network reorganization in the adult rat hippocampus. J. Neurosci. 1997, 17, 3727-3738. [CrossRef] [PubMed]

8. Jessberger, S.; Parent, J.M. Epilepsy and Adult Neurogenesis. Cold Spring Harb. Perspect. Biol. 2015, 7, a020677. [CrossRef] [PubMed]

9. Sperlagh, B.; Illes, P. P2X7 receptor: An emerging target in central nervous system diseases. Trends Pharmacol. Sci. 2014, 35, 537-547. [CrossRef] [PubMed]

10. Illes, P.; Khan, T.M.; Rubini, P. Neuronal P2X7 Receptors Revisited: Do They Really Exist? J. Neurosci. 2017, 37, 7049-7062. [CrossRef] [PubMed]

11. Sim, J.A.; Young, M.T.; Sung, H.Y.; North, R.A.; Surprenant, A. Reanalysis of P2X7 receptor expression in rodent brain. J. Neurosci. 2004, 24, 6307-6314. [CrossRef] [PubMed]

12. Devinsky, O.; Vezzani, A.; Najjar, S.; De Lanerolle, N.C.; Rogawski, M.A. Glia and epilepsy: Excitability and inflammation. Trends Neurosci. 2013, 36, 174-184. [CrossRef] [PubMed]

13. Beamer, E.; Goloncser, F.; Horvath, G.; Beko, K.; Otrokocsi, L.; Kovanyi, B.; Sperlagh, B. Purinergic mechanisms in neuroinflammation: An update from molecules to behavior. Neuropharmacology 2016, 104, 94-104. [CrossRef] [PubMed]

14. Ferrari, D.; Pizzirani, C.; Adinolfi, E.; Lemoli, R.M.; Curti, A.; Idzko, M.; Panther, E.; Di Virgilio, F. The P2X7 receptor: A key player in IL-1 processing and release. J. Immunol. 2006, 176, 3877-3883. [CrossRef] [PubMed]

15. Giuliani, A.L.; Sarti, A.C.; Falzoni, S.; Di Virgilio, F. The P2X7 Receptor-Interleukin-1 Liaison. Front. Pharmacol. 2017, 8, 123. [CrossRef] [PubMed]

16. Young, C.N.J.; Gorecki, D.C. P2RX7 Purinoceptor as a Therapeutic Target-The Second Coming? Front. Chem. 2018, 6, 248. [CrossRef] [PubMed]

17. Di Virgilio, F.; Dal, B.D.; Sarti, A.C.; Giuliani, A.L.; Falzoni, S. The P2X7 Receptor in Infection and Inflammation. Immunity 2017, 47, 15-31. [CrossRef] [PubMed]

18. Rozmer, K.; Gao, P.; Araujo, M.G.L.; Khan, M.T.; Liu, J.; Rong, W.; Tang, Y.; Franke, H.; Krugel, U.; Fernandes, M.J.S.; et al. Pilocarpine-Induced Status Epilepticus Increases the Sensitivity of P2X7 and P2Y1 Receptors to Nucleotides at Neural Progenitor Cells of the Juvenile Rodent Hippocampus. Cereb. Cortex 2017, 27, 3568-3585. [CrossRef] [PubMed]

19. Khan, M.T.; Liu, J.; Tang, Y.; Illes, P. Regulation of P2X7 receptor function of neural progenitor cells in the hippocampal subgranular zone by neuronal activity in the dentate gyrus. Neuropharmacology 2018, 140, 139-149. [CrossRef] [PubMed] 
20. Dossi, E.; Heine, C.; Servettini, I.; Gullo, F.; Sygnecka, K.; Franke, H.; Illes, P.; Wanke, E. Functional regeneration of the ex-vivo reconstructed mesocorticolimbic dopaminergic system. Cereb. Cortex 2013, 23, 2905-2922. [CrossRef] [PubMed]

21. Gao, P.; Ding, X.; Khan, T.M.; Rong, W.; Franke, H.; Illes, P. P2X7 receptor-sensitivity of astrocytes and neurons in the substantia gelatinosa of organotypic spinal cord slices of the mouse depends on the length of the culture period. Neuroscience 2017, 349, 195-207. [CrossRef] [PubMed]

22. Oliveira, J.F.; Riedel, T.; Leichsenring, A.; Heine, C.; Franke, H.; Krugel, U.; Norenberg, W.; Illes, P. Rodent cortical astroglia express in situ functional P2X7 receptors sensing pathologically high ATP concentrations. Cereb. Cortex 2011, 21, 806-820. [CrossRef] [PubMed]

23. Martin, A.; Domercq, M.; Matute, C. Inflammation in stroke: The role of cholinergic, purinergic and glutamatergic signaling. Ther. Adv. Neurol. Disord. 2018, 11, 1756286418774267. [CrossRef] [PubMed]

24. Vezzani, A. Epilepsy and inflammation in the brain: Overview and pathophysiology. Epilepsy Curr. 2014, 14, 3-7. [CrossRef] [PubMed]

25. Webster, K.M.; Sun, M.; Crack, P.; O’Brien, T.J.; Shultz, S.R.; Semple, B.D. Inflammation in epileptogenesis after traumatic brain injury. J. Neuroinflammation 2017, 14, 10. [CrossRef] [PubMed]

26. Leichsenring, A.; Riedel, T.; Qin, Y.; Rubini, P.; Illes, P. Anoxic depolarization of hippocampal astrocytes: Possible modulation by P2X7 receptors. Neurochem. Int. 2013, 62, 15-22. [CrossRef] [PubMed]

27. Roger, S.; Pelegrin, P.; Surprenant, A. Facilitation of P2X7 receptor currernts and membrane blebbing via constitutive and dynamic calmodulin binding. J. Neurosci. 2008, 28, 6393-6401. [CrossRef] [PubMed]

28. Probert, L.; Akassoglou, K.; Pasparakis, M.; Kontogeorgos, G.; Kollias, G. Spontaneous inflammatory demyelinating disease in transgenic mice showing central nervous system-specific expression of tumor necrosis factor alpha. Proc. Natl. Acad. Sci. USA 1995, 92, 11294-11298. [CrossRef] [PubMed]

29. Godukhin, O.V.; Levin, S.G.; Parnyshkova, E.Y. The effects of interleukin-10 on the development of epileptiform activity in the hippocampus induced by transient hypoxia, bicuculline, and electrical kindling. Neurosci. Behav. Physiol. 2009, 39, 625-631. [CrossRef] [PubMed]

30. Galic, M.A.; Riazi, K.; Heida, J.G.; Mouihate, A.; Fournier, N.M.; Spencer, S.J.; Kalynchuk, L.E.; Teskey, G.C.; Pittman, Q.J. Postnatal inflammation increases seizure susceptibility in adult rats. J. Neurosci. 2008, 28, 6904-6913. [CrossRef] [PubMed]

31. Harre, E.M.; Galic, M.A.; Mouihate, A.; Noorbakhsh, F.; Pittman, Q.J. Neonatal inflammation produces selective behavioural deficits and alters $\mathrm{N}$-methyl-D-aspartate receptor subunit mRNA in the adult rat brain. Eur. J. Neurosci. 2008, 27, 644-653. [CrossRef] [PubMed]

32. Vezzani, A.; Viviani, B. Neuromodulatory properties of inflammatory cytokines and their impact on neuronal excitability. Neuropharmacology 2015, 96, 70-82. [CrossRef] [PubMed]

33. Solle, M.; Labasi, J.; Perregaux, D.G.; Stam, E.; Petrushova, N.; Koller, B.H.; Griffiths, R.J.; Gabel, C.A. Altered cytokine production in mice lacking P2X7 receptors. J. Biol. Chem. 2001, 276, 125-132. [CrossRef] [PubMed]

34. Yan, Z.; Khadra, A.; Sherman, A.; Stojilkovic, S.S. Calcium-dependent block of P2X7 receptor channel function is allosteric. J. Gen. Physiol. 2011, 138, 437-452. [CrossRef] [PubMed]

35. Leschinger, A.; Stabel, J.; Igelmund, P.; Heinemann, U. Pharmacological and electrographic properties of epileptiform activity induced by elevated $\mathrm{K}^{+}$and lowered $\mathrm{Ca}^{2+}$ and $\mathrm{Mg}^{2+}$ concentration in rat hippocampal slices. Exp. Brain. Res. 1993, 96, 230-240. [CrossRef] [PubMed]

36. Franke, H.; Illes, P. Nucleotide signaling in astrogliosis. Neurosci. Lett. 2014, 565, 14-22. [CrossRef] [PubMed]

37. Franke, H.; Illes, P. Pathological potential of astroglial purinergic receptors. Adv. Neurobiol. 2014, 11, $213-256$. [PubMed]

38. Franke, H.; Verkhratsky, A.; Burnstock, G.; Illes, P. Pathophysiology of astroglial purinergic signalling. Purinergic Signal. 2012, 8, 629-657. [CrossRef] [PubMed]

39. Franke, H.; Günther, A.; Grosche, J.; Schmidt, R.; Rossner, S.; Reinhardt, R.; Faber-Zuschratter, H.; Schneider, D.; Illes, P. P2X7 receptor expression after ischemia in the cerebral cortex of rats. J. Neuropathol. Exp. Neurol. 2004, 63, 686-699. [CrossRef] [PubMed]

40. Bai, H.Y.; Li, A.P. P2X7 receptors in cerebral ischemia. Neurosci. Bull. 2013, 29, 390-398. [CrossRef] [PubMed]

41. Melani, A.; Amadio, S.; Gianfriddo, M.; Vannucchi, M.G.; Volonte, C.; Bernardi, G.; Pedata, F.; Sancesario, G. P2X7 receptor modulation on microglial cells and reduction of brain infarct caused by middle cerebral artery occlusion in rat. J. Cereb. Blood Flow Metab. 2006, 26, 974-982. [CrossRef] [PubMed] 
42. Kaiser, M.; Penk, A.; Franke, H.; Krugel, U.; Norenberg, W.; Huster, D.; Schaefer, M. Lack of functional P2X7 receptor aggravates brain edema development after middle cerebral artery occlusion. Purinergic Signal. 2016, 12, 453-463. [CrossRef] [PubMed]

43. Yu, Q.; Guo, Z.; Liu, X.; Ouyang, Q.; He, C.; Burnstock, G.; Yuan, H.; Xiang, Z. Block of P2X7 receptors could partly reverse the delayed neuronal death in area CA1 of the hippocampus after transient global cerebral ischemia. Purinergic Signal. 2013, 9, 663-675. [CrossRef] [PubMed]

44. Chu, K.; Yin, B.; Wang, J.; Peng, G.; Liang, H.; Xu, Z.; Du, Y.; Fang, M.; Xia, Q.; Luo, B. Inhibition of P2X7 receptor ameliorates transient global cerebral ischemia/reperfusion injury via modulating inflammatory responses in the rat hippocampus. J. Neuroinflammation 2012, 9, 69. [CrossRef] [PubMed]

45. Wirkner, K.; Kofalvi, A.; Fischer, W.; Gunther, A.; Franke, H.; Groger-Arndt, H.; Norenberg, W.; Madarasz, E.; Vizi, E.S.; Schneider, D.; et al. Supersensitivity of P2X receptors in cerebrocortical cell cultures after in vitro ischemia. J. Neurochem. 2005, 95, 1421-1437. [CrossRef] [PubMed]

46. Dubé, C.M.; Brewster, A.L.; Richichi, C.; Zha, Q.; Baram, T.Z. Fever, febrile seizures and epilepsy. Trends Neurosci. 2007, 30, 490-496. [CrossRef] [PubMed]

(C) 2018 by the authors. Licensee MDPI, Basel, Switzerland. This article is an open access article distributed under the terms and conditions of the Creative Commons Attribution (CC BY) license (http:/ / creativecommons.org/licenses/by/4.0/). 